\title{
The BODE Index, a Multidimensional Grading System, Reflects Impairment of Right Ventricle Functions in Patients with Chronic Obstructive Pulmonary Disease: A Speckle-Tracking Study
}

\author{
Tayyar Gökdeniz ${ }^{a}$ Ezgi Kalaycıoğlu ${ }^{b}$ Faruk Boyacı $^{\text {b }}$ Ahmet Çağrı Aykan ${ }^{b}$ \\ Mustafa Ozan Gürsoy ${ }^{d}$ Engin Hatem ${ }^{b}$ Abdurrezak Börekçia Yavuz Karabaga \\ Selma Altun ${ }^{c}$ \\ a Department of Cardiology, Faculty of Medicine, Kafkas University, Kars, Departments of ${ }^{b}$ Cardiology and ${ }^{\mathrm{C}}$ Respiratory \\ Medicine, Ahi Evren Chest and Cardiovascular Surgery Education and Research Hospital, Trabzon, and d Department of \\ Cardiology, Gaziemir Salih Nevvar İşgören State Hospital, İzmir, Turkey
}

\section{Key Words}

BODE index · Chronic obstructive pulmonary disease .

Two-dimensional speckle tracking echocardiography .

Right ventricular free wall strain

\begin{abstract}
Background:Chronic obstructive pulmonary disease (COPD) is not only characterized by chronic airflow limitation, but is also a systemic disease. There is no information about alterations in right ventricle (RV) functions precipitated by systemic manifestations of COPD. Objectives: We aimed to evaluate the relationship between the BODE (body mass index, airflow obstruction, dyspnea, and exercise capacity) index that evaluates systemic manifestations of COPD and RV functions by means of 2-dimensional speckle-tracking echocardiography (2D-STE) in COPD patients. Methods: The study involved 135 COPD patients and 37 control subjects. All patients underwent 2D-STE, pulmonary function tests and 6-min walk tests, and were divided into quartiles according to their calculated BODE index score. Results: COPD patients had im-
\end{abstract}

paired RV and left-ventricle diastolic functions compared to controls. There was a decreasing trend from quartile $1\left(Q_{1}\right)$ to $\mathrm{Q}_{4}$ in $\mathrm{RV}$ functional parameters, i.e. RV free wall strain (RVFW-S, p < 0.001), tricuspid annular plane systolic excursion $(p<0.001)$, systolic myocardial velocity $(p<0.001)$, RV fractional area change $(p<0.001)$, RV myocardial performance index $(p<0.001)$ and pulmonary artery systolic pressure $(p<0.001)$. The transmitral Doppler E wave/lateral mitral annular tissue Doppler E wave ratio was similar in the 4 BODE index quartiles $(p=0.159)$. Multivariate analysis was performed to find independent predictors of decreased RVFW-S ( $\leq 19.06$ ), and the BODE index (in quartiles; OR 4.61 and $95 \% \mathrm{Cl} 1.85-11.63$ ) was found to be an independent predictor. In a partial correlation analysis adjusted for forced expiratory volume in $1 \mathrm{~s} \%$ predicted, RVFW-S was correlated with the 6-min walk distance $(r=0.498)$. Conclusion: The BODE index, which can be easily evaluated in office settings, may provide information about reduced $\mathrm{RV}$ functions as well as guiding treatment and helping to predict prognosis in COPD patients.

\section{KARGER}

E-Mail karger@karger.com www.karger.com/res
(C) 2014 S. Karger AG, Basel

0025-7931/14/0883-0223\$39.50/0
Tayyar Gökdeniz, MD

Department of Cardiology

Kafkas University, Faculty of Medicine

TR-36000 Kars (Turkey)

E-Mail tgkdeniz@ hotmail.com 


\section{Introduction}

Chronic obstructive pulmonary disease (COPD) is characterized by a chronic airflow limitation that is not fully reversible. It is an important public health problem due to increased morbidity and mortality as well as augmented economic and social loads. It is predicted that it will be the third-most frequent cause of death in the world by $2020[1,2]$. Therefore, it is very important to identify the predictors of increased morbidity and mortality in patients suffering from this disease. Previous studies demonstrated that some physiological and clinical parameters including forced expiratory volume in $1 \mathrm{~s}\left(\mathrm{FEV}_{1}\right)$, hypoxemia, increased shortness of breath and a short 6-min walk distance are associated with increased mortality risk in COPD patients $[3,4]$. However, these parameters provide limited data about COPD as a systemic disease [5]. Recently, the BODE [body mass index (BMI), airflow obstruction, dyspnea, and exercise capacity] index, a multidimensional grading system, was introduced by Celli et al. [6] to predict the risk of death in patients with COPD. The BODE index evaluates individuals with COPD from multidimensional aspects such as symptoms, nutritional state, degree of airflow limitation and exercise capacity [6, 7]. Recent studies showed that the BODE index can measure disease severity as well as predict survival, annual exacerbation and hospitalization rates $[8,9]$.

In patients with COPD, cardiovascular-system-related death is the second-most frequent cause of mortality after lung cancer $[10,11]$. Previous studies demonstrated that right ventricle (RV) dysfunction is associated with increased cardiovascular events as well as predicting mortality in COPD patients $[12,13]$. Therefore, assessment of RV functions in these patients is clinically essential. The evaluation of RV functions with conventional echocardiography is challenging due to the complex geometry of the RV and the lung hyperinflation that occurs in patients with COPD $[14,15]$. Two-dimensional speckle-tracking echocardiography (2D-STE) is a novel technique used for the measurement of cardiac mechanics. It assesses myocardial deformation and the myocardial deformation rate by tracking speckles in the myocardium on grayscale (B-mode) images. It can be used to evaluate both global and regional myocardial strain and strain rate without being limited by Doppler beam angle, tethering effect or load dependency [16].

There is no information about the relationship between the BODE index and RV functions. We aimed to evaluate the potential relationship between them, by assessment of 2D-STE-derived strain images in patients with COPD.

\section{Methods}

\section{Study Design}

This was a single-center, cross-sectional study conducted between August 2011 and April 2013. A total of 135 consecutive COPD patients followed up by the Department of Respiratory Medicine were enrolled. The control group consisted of 37 ageand sex-matched healthy individuals. We excluded patients in whom there was echocardiographic evidence of either regional or global wall motion abnormalities, reduced left ventricle (LV) function, a history of coronary artery disease, angina pectoris, a positive treadmill test or nuclear perfusion stress test, ischemic electrocardiographic findings, chronic renal failure, atrial fibrillation/flutter, 2nd- or 3rd-degree atrioventricular block, RV pacing, moderateto-severe valvular heart disease, pulmonary embolism, idiopathic pulmonary hypertension, obstructive sleep apnea, pulmonary artery stenosis or RV outflow obstruction, tricuspid structural disease, COPD exacerbation at the time of investigation or poor echoechocardiographic view. The diagnosis of COPD was based on a history of cigarette smoking of at least 10 pack-years, symptoms and radiographic findings suggestive of COPD and spirometric findings with a postbronchodilator $\mathrm{FEV}_{1} / \mathrm{FVC}$ (forced vital capacity) $<70 \%$ predicted and $\mathrm{FEV}_{1}<80 \%$ predicted [1]. At the time of enrollment, all study patients had been free of exacerbations of COPD for at least 6 months.

Informed consent was obtained from the patients and the local ethics committee approved the study protocol. Baseline clinical and demographic information was obtained from all patients. The medical history of the patients was recorded and a detailed physical examination was performed. Blood analysis was performed after $12 \mathrm{~h}$ of fasting. Fasting blood glucose, lipid parameters and creatinine and hemoglobin values were measured. Blood pressure was measured with a sphygmomanometer using an appropriately sized cuff. Values for systolic and diastolic blood pressure were obtained from the average of the second and third measurements. Hypertension was identified on the basis of having to receive antihypertensive treatment or when the blood pressure exceeded 140/90 mm Hg in at least 3 measurements. Diabetes was defined as having had to receive oral antidiabetic medication or insulin or having a fasting glucose level of $>126 \mathrm{mg} / \mathrm{dl}$. Smoking behavior was defined as 'current' or 'exsmoker' and the number of smoking pack-years was recorded. BMI was calculated and the estimated glomerular filtration rate was calculated by the Modification of Diet in Renal Disease study equation [17].

All COPD patients were evaluated by spirometry, arterial blood gas analysis, echocardiography and 6-min walk distance, respectively, and all measurements were performed at rest and while breathing room air. The control group underwent echocardiographic assessment only.

\section{Pulmonary Function Tests}

Pulmonary function tests were performed, as previously reported [18]. $\mathrm{FEV}_{1}$ and $\mathrm{FVC}$ were measured with a clinical spirometer (ZAN 100, Morgan strumenti scientifici, Italy).

\section{Arterial Blood Gas Analysis}

Blood was drawn via the radial or brachial artery. Arterial oxygen pressure, arterial carbon dioxide pressure and arterial oxygen saturation were calculated. 
Table 1. Multidimensional components and scoring system for calculation of the BODE index

\begin{tabular}{lclcc}
\hline $\begin{array}{l}\mathrm{FEV}_{1} \\
\% \text { predicted }\end{array}$ & $\begin{array}{l}\text { mMRC } \\
\text { dyspnea score }\end{array}$ & BMI & $\begin{array}{l}\text { 6-min walk } \\
\text { distance, } \mathrm{m}\end{array}$ \\
\hline 0 & $\geq 65$ & $0-1$ & $>21$ & $\geq 350$ \\
1 & $50-64$ & 2 & $\leq 21$ & $250-349$ \\
2 & $36-49$ & 3 & - & $150-249$ \\
3 & $\leq 35$ & 4 & - & $\leq 149$ \\
\hline
\end{tabular}

\section{BODE Index}

The BODE index was calculated by a summation of scores obtained from BMI, the modified Medical Research Council (mMRC) dyspnea scale [19], spirometric measurements and 6-min walk distance (table 1). Six-minute walk tests were performed twice at least 30 min apart and the longest walk distance was used for scoring [7]. The BODE index ranged from 0 to 10 points and the patients were divided into quartiles according to their score: quartile $1\left(Q_{1}\right)=0-2$ points, $\mathrm{Q}_{2}=3-4$ points, $\mathrm{Q}_{3}=5-6$ points and $\mathrm{Q}_{4}=7-10$ points [6].

\section{Conventional Echocardiography}

The echocardiographic studies including 2D, M-mode, pulsedwave Doppler and pulsed tissue Doppler imaging (TDI) examinations were performed from all standard echocardiographic windows using a commercially available echocardiography machine (GE Vivid S5, Vingmed Ultrasound A.S., Horten, Norway) equipped with a 3.6-MHz transducer. LV and RV measurements were performed according to the American Society of Echocardiography guidelines $[20,21]$. During the echocardiographic examination, a 1-lead electrocardiogram was recorded continuously. LV dimensions (end-diastolic and end-systolic) and wall thickness (septum and posterior wall) were obtained from the parasternal long axis with an M-mode cursor positioned just beyond the mitral leaflet tips, perpendicular to the long axis of the LV. LV volume and ejection fraction were measured using the modified Simpson method from the apical 4-chamber and 2-chamber views. Mitral inflow velocities were evaluated by pulsed-wave Doppler with the sample volume placed at the tip of the mitral leaflets from the apical 4-chamber view. Using the average of three beats, we measured the diastolic early- and late-peak, i.e. the Doppler E wave (E) and Doppler A wave (A) transmitral flow velocity and the E/A ratio. Mitral annulus velocity was measured at the lateral corner of the annulus by TDI using the pulsed-wave Doppler mode. The lateral mitral annular tissue Doppler S wave and E wave (Em) were measured from the apical 4-chamber view with a 2- to 5-mm sample volume. Measurements were recorded with simultaneous electrocardiography at a sweep of $50-100 \mathrm{~mm} / \mathrm{s}$. To evaluate LV filling pressures, E/Em ratio was calculated. For RV parameters, TDI recordings were obtained from apical 4-chamber-view-focused RV with the pulsed-wave Doppler sample volume placed on the tricuspid lateral annulus. Peak systolic myocardial velocity (Sm RV) was measured. The sum of RV isovolumic contraction and relaxation time was obtained by subtracting RV ejection time from the interval between the cessation and onset of the tricuspid inflow velocities using pulsed-wave Doppler. The RV myocardial performance index (MPI) was obtained by dividing the sum of both isovolumic intervals by the ejection time. From the modified apical 4-chamber view including the RV apex, the RV end-diastolic and end-systolic areas were calculated. RV fractional area change (FAC) was calculated as the percentage value of difference between RV end-diastolic and end-systolic areas divided by the RV end-diastolic area. To determine the motion and excursion of the annulus, the Mmode cursor was oriented to the junction of the tricuspid valve plane with the RV free wall, using images in the apical 4-chamber view. Maximal tricuspid annular plane systolic excursion (TAPSE) was determined by the total excursion of the tricuspid annulus from its highest position after atrial ascent to the peak descent during ventricle systole. Pulmonary artery systolic pressure (PAPs) was estimated using the approach of calculating the systolic pressure gradient between the RV and right atrium by the maximum velocity of the tricuspid regurgitant jet, using the modified Bernoulli equation and then adding an estimated right atrial pressure to this value, based on both the size of the inferior vena cava and the change in caliber of this vessel with respiration.

\section{Two-Dimensional Speckle-Tracking Analysis}

2D-STE images of the RV were acquired at end-diastole in the $\mathrm{RV}$ from the RV-focused view. Second harmonic imaging was used to improve endocardial border detection (1.7-2.0 $\mathrm{MHz}$ ). Three consecutive cardiac cycles were recorded at end expiration. The frame rate was kept between 70-100 frames/s. Using commercially available 2D strain software (EchoPAC 108.1.12, General Electric Medical Systems, Horten, Norway), the endocardial border in the end-systolic frame was manually traced from the RVfocused view, and a region of interest) was traced with a point-andclick approach on the endocardium at end-diastole in the RV from the RV-focused view. A second, larger region of interest was then generated and manually adjusted near the epicardium. Special care was taken to fine-tune the region of interest, using visual assessment during cineloop playback to ensure that segments were tracked appropriately. Segments that failed to track were manually adjusted by the operator. Any view in which 2 or more segments could not be tracked was not included in the analysis. Finally, segments were tracked on a frame-by-frame basis using the sum of absolute difference algorithm. The RV was divided into 6 standard segments (at the basal, middle and apical levels), and 6 corresponding time-strain curves were generated. RV free wall (RVFW-S) and RV septal wall strain were separately calculated by averaging each of the 3 regional peak systolic strains along the entire RV free and septal walls, respectively. All measurements were performed by one experienced cardiologist blinded to data about the clinical status of the patients.

\section{Statistical Analysis}

SPSS 17.0 statistical software (SPSS Inc., Chicago, Ill., USA) was used for statistical analysis. Continuous variables are expressed as mean \pm standard deviation (SD) and categorical variables are expressed as percentages. The Kolmogorov-Smirnov test was used to test the normality of distribution of continuous variables. Group means for continuous variables were compared with the use of the Student $t$ test, the Mann-Whitney U test, ANOVA or the KruskalWallis test, as appropriate. Categorical variables were compared with the $\chi^{2}$ test. The Tukey honestly significant difference test was used for post hoc analysis. The Pearson or Spearman correlation analysis was used for assessing the correlation between RVFW-S and continuous variables depending on Gaussian distributions. 
The COPD patients were divided into 2 groups according to the median value of RVFW-S ( $>19.06$ and $\leq 19.06)$. Two multivariate logistic regression analyses were performed to find independent associates of impaired RVFW-S ( $\leq 19.06)$. In model 1, age, TAPSE, RV FAC, BODE index, RV MPI, PAPs and Sm RV were entered into the model as independent variables. BODE index components including BMI, mMRC dyspnea score, $\mathrm{FEV}_{1} \%$ predicted and 6-min walk distance were entered into model 2 as independent variables. The partial correlation analysis was used for assessing the correlation between RVFW-S and 6-min walk distance after adjustment for $\mathrm{FEV}_{1} \%$ predicted. Interobserver agreement of echocardiographic parameters obtained from 2D-STE data was calculated by means of the Bland-Altman analysis and the intraclass correlation coefficient was used to assess intraobserver agreement. Receiver-operating characteristic curve analysis was performed to detect the cut-off value of $\mathrm{FEV}_{1} \%$ predicted and 6-min walk distance for the prediction of RVFW-S ( $\leq 19.06)$. Area under the curve (AUC) comparison was performed with the MedCalc software program, release 7.3.0.1 (MedCalc Software, Belgium). A two-tailed $\mathrm{p}<0.05$ was considered statistically significant.

\section{Results}

The study population consisted of 135 COPD patients and 37 control subjects. The baseline characteristics of patients and controls are shown in table 2. Laboratory parameters did not differ between the 2 groups. With regard to clinical features, only 2 variables differed between the groups: the incidence of current and previous smoking was significantly higher in the COPD group $(\mathrm{p}<0.001$ and $p<0.001$, respectively). The patients with COPD had decreased RV functional parameters including RVFW-S $(\mathrm{p}<0.001)$, TAPSE $(\mathrm{p}<0.001)$, Sm RV $(\mathrm{p}<0.001)$, RV FAC $(\mathrm{p}<0.001)$ and increased RV MPI $(\mathrm{p}<0.001)$ and PAPs $(\mathrm{p}<0.001)$ compared to the control group. Of the $\mathrm{LV}$ diastolic parameters, the E/A ratio was significantly decreased $(p<0.001)$ and the E/Em ratio was significantly higher in the COPD group than in the control group $(p=0.003)$. The other measurements of LV were similar in the 2 groups. When patients were classified with respect to the BODE index, 28.1\% $(\mathrm{n}=38)$ were BODE 1 $\left(\mathrm{Q}_{1}\right), 26.7 \%(\mathrm{n}=36)$ were BODE $2\left(\mathrm{Q}_{2}\right), 22.2 \%(\mathrm{n}=30)$ were BODE $3\left(\mathrm{Q}_{3}\right)$ and $23.0 \%(\mathrm{n}=31)$ were BODE $4\left(\mathrm{Q}_{4}\right)$. Multiple comparisons were performed between the BODE index quartiles and the control group. The control group had a smoking history of a lower number of packyears than the BODE index quartiles (which did not differ across quartiles, $\mathrm{p}<0.001)$. Other clinic and laboratory parameters of the BODE index quartiles and the control group were similar. Although the $\mathrm{E} / \mathrm{Em}$ ratio showed a decreasing trend from $\mathrm{Q}_{1}$ to $\mathrm{Q}_{4}$, there was no significant difference between the BODE index quartiles $(p=0.159)$.
As for the RV functional parameters, RVFW-S, TAPSE, Sm RV and RV FAC showed a decreasing trend from the control group to the $\mathrm{Q}_{4}$ patients, while for RV MPI and PAPs there was an increasing trend (table 3 ). The BODE index components, i.e. BMI $(26.4 \pm 4.0,25.8 \pm 4.9,25.4 \pm$ $4.6,23.1 \pm 5.1)$, mMRC dyspnea score $(1.0 \pm 0.5,1.7 \pm 0.5$, $2.6 \pm 0.5,3.3 \pm 0.4), \mathrm{FEV}_{1} \%$ predicted $(65.4 \pm 10.8,48.9$ $\pm 11.2,38.7 \pm 7.5,31.4 \pm 6.8)$ and 6 -min walk distance $(423.6 \pm 98.2,315.1 \pm 58.1,231.0 \pm 62.3,101.7 \pm 39.7)$, were measured in $\mathrm{Q}_{1}-\mathrm{Q}_{4}$.

Univariate correlation analysis of COPD patients revealed that RVFW-S was positively correlated with TAPSE $(r=0.462, p<0.001)$, Sm RV $(r=0.384, p<0.001)$ and RV FAC $(\mathrm{r}=0.501, \mathrm{p}<0.001)$. RV MPI and PAPs were negatively correlated with RVFW-S $(r=-0.372$, $\mathrm{p}<0.001$ vs. $\mathrm{r}=-0.414, \mathrm{p}<0.001$, respectively). For the COPD patients, a correlation analysis between the echocardiographic parameters (both conventional echocardiography and 2D-STE) of RV, $\mathrm{FEV}_{1} \%$ predicted and 6-min walk distance was performed (table 4).

\section{Predictors of Decreased RVFW-S}

Patients with COPD were divided into 2 groups according to the RVFW-S value $(>19.06$ and $\leq 19.06)$ which was the median value of RVFW-S in COPD subjects. To find independent predictors of decreased RVFW-S $(\leq 19.06)$, two multivariate logistic regression analyses were performed. In model 1 , independent variables such as BODE index quartiles, age, TAPSE, RV FAC, RV MPI, PAPs and Sm RV were entered into the model. The $\mathrm{R}^{2}$ of logistic regression was 0.491 and the BODE index quartiles were found to be independent predictors of decreased RVFW-S (table 5). Table 6 shows the characteristics of COPD patients according to the RVFW-S value. RVFW-S was compared with the nominal components of the BODE index. Patients with an mMRC score of 3-4 had significantly lower RVFW-S values than those with a score of $0-2(17.5 \pm 1.4$ vs. $20.2 \pm 2.0, p<0.001)$. Regarding the BMI, RVFW-S was significantly lower in patients with $\mathrm{BMI} \leq 21$ than in those with $\mathrm{BMI}>21(18.4 \pm 2.1 \mathrm{vs}$. $19.5 \pm 2.2, \mathrm{p}=0.014$ ) (fig. 1). To establish which BODE index parameter is the most important for predicting RVFW-S ( 1 19.06), BMI, mMRC dyspnea score, $\mathrm{FEV}_{1} \%$ predicted and 6-min walk distance were entered into model 2 as independent variables. Age (OR 1.05, 95\% CI $1.00-1.09, \mathrm{p}=0.039), \mathrm{FEV}_{1} \%$ predicted (OR 0.97, 95\% CI $1.00-0.94, \mathrm{p}=0.037$ ) and 6-min walk distance (OR 0.99, 95\% CI 1.00-0.98, $\mathrm{p}=0.001)$ were independently associated with RVFW-S ( $\leq 19.06)$. Receiver-operating characteristic curve analysis was performed to detect the cut-off 
Table 2. Baseline characteristics of patients with COPD and controls

\begin{tabular}{|c|c|c|c|}
\hline Variables & $\begin{array}{l}\text { Controls } \\
(\mathrm{n}=37)\end{array}$ & $\begin{array}{l}\text { Patients with COPD } \\
(\mathrm{n}=135)\end{array}$ & $\mathrm{p}$ value \\
\hline Age, years & $67.7 \pm 3.9$ & $69.6 \pm 10.6$ & 0.100 \\
\hline Male & $32(86.5)$ & $125(92.6)$ & 0.244 \\
\hline Hypertension & $13(35.1)$ & $54(40)$ & 0.591 \\
\hline Diabetes mellitus & $4(10.8)$ & $19(14.1)$ & 0.605 \\
\hline Current smoker & $9(24.3)$ & $58(43)$ & 0.039 \\
\hline Exsmoker & $4(10.8)$ & $73(54.1)$ & $<0.001$ \\
\hline Pack-years of smoking & $15.0 \pm 21.4$ & $56.2 \pm 25.4$ & $<0.001$ \\
\hline BMI & $24.4 \pm 1.3$ & $25.3 \pm 4.7$ & 0.278 \\
\hline $\mathrm{eGFR} \geq 60 \mathrm{ml} / \mathrm{min} / 1.73 \mathrm{~m}^{2}$ & $35(94.6)$ & $117(86.7)$ & 0.183 \\
\hline $\mathrm{SBP}, \mathrm{mm} \mathrm{Hg}$ & $133.1 \pm 12.8$ & $136.7 \pm 18.2$ & 0.266 \\
\hline DBP, mm Hg & $79.9 \pm 14.3$ & $82.9 \pm 11.4$ & 0.175 \\
\hline $\mathrm{FEV}_{1} \%$ predicted & - & $47.3 \pm 17.6$ & - \\
\hline $\mathrm{FEV}_{1} / \mathrm{FVC}, \%$ & - & $61.1 \pm 9.9$ & - \\
\hline FVC $\%$ predicted & - & $83.6 \pm 7.4$ & - \\
\hline LDL-cholesterol, mg/dl & $123.5 \pm 14.7$ & $119.6 \pm 26.2$ & 0.243 \\
\hline HDL-cholesterol, mg/dl & $43.0 \pm 6.5$ & $40.5 \pm 10.3$ & 0.081 \\
\hline Triglycerides, $\mathrm{mg} / \mathrm{dl}$ & $145.4 \pm 23.8$ & $135.1 \pm 49.9$ & 0.078 \\
\hline Total cholesterol, mg/dl & $185.4 \pm 15.3$ & $177.9 \pm 34.3$ & 0.200 \\
\hline Hemoglobin, mg/dl & $12.8 \pm 0.7$ & $13.3 \pm 1.6$ & 0.060 \\
\hline Fasting plasma glucose, $\mathrm{mg} / \mathrm{dl}$ & $97.5 \pm 17.1$ & $103.3 \pm 18.1$ & 0.081 \\
\hline Calcium-channel blockers & $7(18.9)$ & $19(14.1)$ & 0.466 \\
\hline Beta-blockers & $3(8.1)$ & $5(3.7)$ & 0.260 \\
\hline ACE inhibitors or ARB & $9(24.3)$ & $35(25.9)$ & 0.843 \\
\hline Statins & $7(18.9)$ & $25(18.5)$ & 0.956 \\
\hline Oral antidiabetics & $3(8.1)$ & $14(10.4)$ & 0.683 \\
\hline Insulin & $3(8.1)$ & $5(3.7)$ & 0.260 \\
\hline $\mathrm{LV}$ end-diastolic volume, $\mathrm{ml} / \mathrm{m}^{2}$ & $94.6 \pm 15.8$ & $87.7 \pm 23.4$ & 0.091 \\
\hline $\mathrm{LV}$ end-systolic volume, $\mathrm{ml} / \mathrm{m}^{2}$ & $37.2 \pm 7.7$ & $36.6 \pm 10.2$ & 0.697 \\
\hline LV end-diastolic dimension, $\mathrm{mm}$ & $47.0 \pm 4.0$ & $46.0 \pm 4.0$ & 0.456 \\
\hline LV end-systolic dimension, mm & $28.0 \pm 4.0$ & $29.0 \pm 3.0$ & 0.318 \\
\hline LV ejection fraction, $\%$ & $60.6 \pm 4.6$ & $59.1 \pm 5.4$ & 0.097 \\
\hline Septal wall thickness, mm & $11.1 \pm 1.0$ & $11.1 \pm 1.7$ & 0.975 \\
\hline Posterior wall thickness, $\mathrm{mm}$ & $10.3 \pm 0.9$ & $10.6 \pm 1.5$ & 0.172 \\
\hline $\mathrm{E} / \mathrm{A}$ ratio & $1.01 \pm 0.20$ & $0.85 \pm 0.20$ & $<0.001$ \\
\hline $\mathrm{Sm}$, systolic tissue velocity, $\mathrm{cm} / \mathrm{s}$ & $11.2 \pm 2.0$ & $10.6 \pm 2.1$ & 0.175 \\
\hline E/Em ratio & $7.6 \pm 1.2$ & $8.4 \pm 1.9$ & 0.003 \\
\hline RVFW-S, \% & $-25.4 \pm 2.6$ & $-19.3 \pm 2.2$ & $<0.001$ \\
\hline RVSW-S, \% & $-20.2 \pm 1.1$ & $-19.9 \pm 0.8$ & 0.142 \\
\hline TAPSE, $\mathrm{cm}$ & $2.4 \pm 0.2$ & $2.0 \pm 0.2$ & $<0.001$ \\
\hline $\mathrm{Sm} \mathrm{RV}, \mathrm{m} / \mathrm{s}$ & $15.9 \pm 2.2$ & $11.8 \pm 3.3$ & $<0.001$ \\
\hline RV FAC, \% & $52.5 \pm 5.9$ & $44.2 \pm 6.7$ & $<0.001$ \\
\hline RV MPI & $0.24 \pm 0.05$ & $0.41 \pm 0.08$ & $<0.001$ \\
\hline PAPs, mm Hg & $21.5 \pm 4.9$ & $32.2 \pm 7.5$ & $<0.001$ \\
\hline
\end{tabular}

Figures denote mean $\pm \mathrm{SD}$ or $\mathrm{n}(\%) . \mathrm{ACE}=$ Angiotensin-converting enzyme; $\mathrm{ARB}=$ angiotensin receptor blocker; DBP = diastolic blood pressure; eGFR = estimated glomerular filtration rate; HDL = high-density lipoprotein; LDL = low-density lipoprotein; RVSW-S = RV septal wall strain; $\mathrm{SBP}=$ systolic blood pressure; $\mathrm{Sm}=$ lateral mitral annular tissue Doppler $\mathrm{S}$ wave. 
Table 3. Comparison of RV functional parameters between the control group and the BODE index quartiles

\begin{tabular}{|c|c|c|c|c|c|c|}
\hline RVFW-S, \% & $-25.5 \pm 2.6$ & $-21.3 \pm 1.9$ & $-19.9 \pm 1.6^{\mathrm{a}}$ & $-18.4 \pm 1.2$ & $-17.1 \pm 1.3$ & $<0.001$ \\
\hline $\mathrm{Sm} \mathrm{RV}, \mathrm{m} / \mathrm{s}$ & $15.9 \pm 2.2$ & $14.2 \pm 3.1$ & $12.5 \pm 31$ & $10.7 \pm 2.0$ & $8.9 \pm 2.1$ & $<0.001$ \\
\hline RV FAC, \% & $52.5 \pm 5.9$ & $48.6 \pm 3.6^{\mathrm{b}}$ & $47.9 \pm 4.3$ & $41.4 \pm 5.8$ & $37.0 \pm 5.4$ & $<0.001$ \\
\hline RV MPI & $0.24 \pm 0.05$ & $0.35 \pm 0.06$ & $0.40 \pm 0.08$ & $0.43 \pm 0.06$ & $0.48 \pm 0.06$ & $<0.001$ \\
\hline
\end{tabular}

${ }^{a}$ Nonsignificance between $\mathrm{Q}_{2}$ and $\mathrm{Q}_{3} \cdot{ }^{\mathrm{b}}$ Nonsignificance between $\mathrm{Q}_{1}$ and $\mathrm{Q}_{2} \cdot{ }^{\mathrm{c}}$ Nonsignificance between $\mathrm{Q}_{1}$ and $\mathrm{Q}_{2} \cdot{ }^{\mathrm{d}}$ Nonsignificance between $\mathrm{Q}_{3}$ and $\mathrm{Q}_{4}$.

Table 4. Correlation analysis of 6-min walk distance and $\mathrm{FEV}_{1}$ with RV echocardiographic parameters in patients with COPD

\begin{tabular}{llc}
\hline Variables & 6-min walk distance, $\mathrm{m}$ & $\mathrm{FEV}_{1} \%$ predicted \\
\hline RVFW-S (\%) & $0.644^{*}$ & $0.543^{*}$ \\
TAPSE $(\mathrm{cm})$ & $0.622^{*}$ & $0.415^{*}$ \\
Sm RV $(\mathrm{m} / \mathrm{s})$ & $0.533^{*}$ & $0.468^{*}$ \\
RV FAC $(\%)$ & $0.588^{*}$ & $0.487^{*}$ \\
RV MPI & $-0.491^{*}$ & $-0.372^{*}$ \\
\hline
\end{tabular}

$* \mathrm{p}<0.001$.

Table 5. The predictors of RVFW-S $(\leq 19.06)$ in the logistic regression analysis

\begin{tabular}{llc}
\hline & $\begin{array}{l}\text { Multivariate } \\
\text { p value }\end{array}$ & $\begin{array}{l}\text { Multivariate OR } \\
(95 \% \mathrm{CI})\end{array}$ \\
\hline Age (years) & 0.052 & $1.05(1.00-1.09)$ \\
BODE index (quartiles) & 0.001 & $4.61(1.85-11.63)$ \\
TAPSE (cm) & 0.223 & $0.19(0.01-2.73)$ \\
RV FAC & 0.633 & $0.98(0.89-1.07)$ \\
RV MPI & 0.307 & $29.41(0.06-98.03)$ \\
PAPs $(\mathrm{mm} \mathrm{Hg})$ & 0.414 & $0.04(0.01-1.06)$ \\
Sm RV $(\mathrm{m} / \mathrm{s})$ & 0.714 & $4.29(1.97-9.32)$ \\
\hline
\end{tabular}

value of $\mathrm{FEV}_{1} \%$ predicted and 6-min walk distance in predicting RVFW-S $(\leq 19.06)$. $\mathrm{FEV}_{1} \%$ predicted identified patients with RVFW-S $(\leq 19.06)$ with a specificity of $80.6 \%$, a sensitivity of $60.3 \%$ with a cut-off value of $49 \%$ (AUC 0.760, 95\% CI 0.679-0.829). In addition, the optimal cut-off value for the 6-min walk distance was 260 , yielding a specificity of $66.7 \%$ and a sensitivity of $87.3 \%$ (AUC $0.810,95 \%$ CI $0.733-0.872$ ). In order to identify

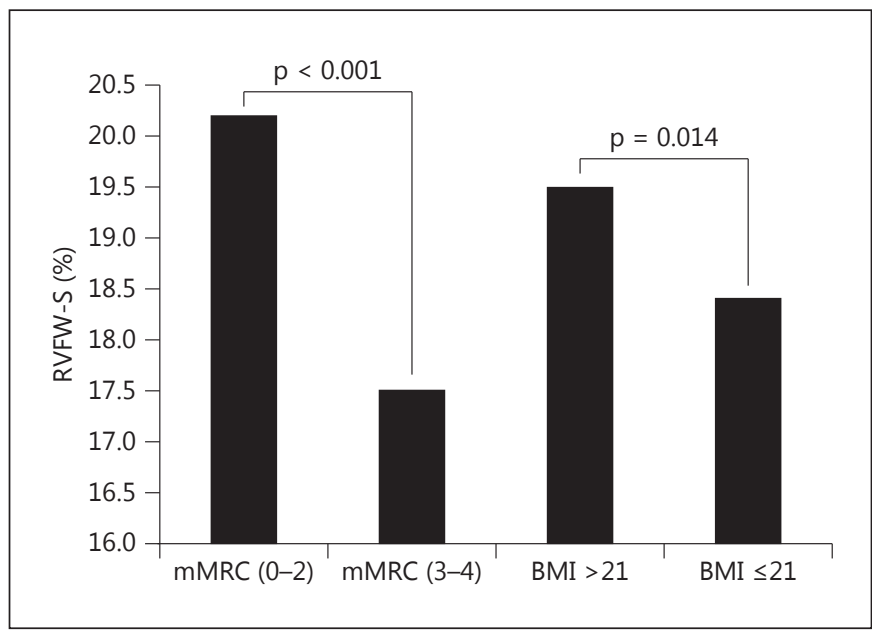

Fig. 1. The mean values of RVFW-S according to mMRC dyspnea scores $0-2$ versus $3-4$ and $B M I>21$ versus $\leq 21$.

which parameters were the most accurate, we compared the AUC of both receiver-operating characteristic curves and there was no significant difference $(\mathrm{p}=0.241)$. The partial correlation analysis was performed for assessing the correlation between RVFW-S and 6-min walk distance after adjustment for $\mathrm{FEV}_{1} \%$ predicted. Figure 2 shows the partial correlation of 6-min walk distance $(\mathrm{r}=0.498$ vs. $\mathrm{p}<0.001)$ with RVFW-S.

\section{Reproducibility}

Intra- and interobserver variability were assessed from echocardiographic data obtained from a subgroup of 20 subjects. To assess interobserver variability, the second operator (who was unaware of the previous measurements) analyzed RV functions with 2D-STE. One month 
Table 6. The characteristics of patients according to the two categories of RVFW-S

\begin{tabular}{|c|c|c|c|}
\hline Variables & RVFW-S >19.06 $(n=63)$ & RVFW $-\mathrm{S} \leq 19.06(\mathrm{n}=72)$ & $\mathrm{p}$ value \\
\hline Age, years & $69.4 \pm 10.7$ & $69.7 \pm 10.7$ & 0.897 \\
\hline Male & $61(96.8)$ & $64(88.9)$ & 0.079 \\
\hline Hypertension & $24(38.1)$ & $30(41.7)$ & 0.673 \\
\hline Diabetes mellitus & $10(15.9)$ & $9(12.5)$ & 0.574 \\
\hline Current smoker & $28(44.4)$ & $30(41.7)$ & 0.745 \\
\hline Exsmoker & $34(54.0)$ & $39(54.2)$ & 0.982 \\
\hline Pack-years of smoking & $53.4 \pm 22.8$ & $58.7 \pm 23.3$ & 0.233 \\
\hline $\mathrm{BMI} \leq 21$ & $7(11.1)$ & $19(26.4)$ & 0.025 \\
\hline $\mathrm{eGFR} \geq 60 \mathrm{ml} / \mathrm{min} / 1.73 \mathrm{~m}^{2}$ & $52(82.5)$ & $65(90.3)$ & 0.187 \\
\hline $\mathrm{SBP}, \mathrm{mm} \mathrm{Hg}$ & $136.9 \pm 20.8$ & $136.4 \pm 15.7$ & 0.881 \\
\hline DBP, mm Hg & $81.7 \pm 12.1$ & $84.0 \pm 10.7$ & 0.246 \\
\hline $\mathrm{FEV}_{1} \%$ predicted & $55.5 \pm 17.3$ & $40.1 \pm 14.6$ & $<0.001$ \\
\hline $\mathrm{FEV}_{1} / \mathrm{FVC}, \%$ & $65.4 \pm 8.5$ & $57.9 \pm 10.5$ & $<0.001$ \\
\hline FVC $\%$ predicted & $86.0 \pm 7.6$ & $81.5 \pm 6.7$ & $<0.001$ \\
\hline $\mathrm{PaO}_{2}$ & $78.5 \pm 11.2$ & $65.3 \pm 9.4$ & $<0.001$ \\
\hline $\mathrm{PaCO}_{2}$ & $38.0 \pm 3.5$ & $43.0 \pm 6.9$ & $<0.001$ \\
\hline $\mathrm{SO}_{2}$ & $95.5 \pm 2.4$ & $91.4 \pm 4.0$ & $<0.001$ \\
\hline LDL-cholesterol, mg/dl & $121.1 \pm 26.6$ & $118.3 \pm 25.9$ & 0.528 \\
\hline HDL-cholesterol, mg/dl & $40.2 \pm 8.5$ & $40.8 \pm 11.7$ & 0.728 \\
\hline Triglycerides, mg/dl & $134.9 \pm 46.9$ & $135.2 \pm 52.7$ & 0.972 \\
\hline Total cholesterol, mg/dl & $181.8 \pm 33.1$ & $174.5 \pm 35.2$ & 0.216 \\
\hline Hemoglobin, mg/dl & $13.1 \pm 1.4$ & $13.4 \pm 1.7$ & 0.378 \\
\hline Fasting plasma glucose, mg/dl & $104.6 \pm 19.0$ & $102.2 \pm 17.4$ & 0.449 \\
\hline $\mathrm{LV}$ end-diastolic volume, $\mathrm{ml} / \mathrm{m}^{2}$ & $88.5 \pm 22.7$ & $87.0 \pm 24.1$ & 0.713 \\
\hline $\mathrm{LV}$ end-systolic volume, $\mathrm{ml} / \mathrm{m}^{2}$ & $36.4 \pm 11.4$ & $36.8 \pm 9.1$ & 0.844 \\
\hline LV end-diastolic dimension, $\mathrm{mm}$ & $46.4 \pm 3.6$ & $45.6 \pm 4.4$ & 0.252 \\
\hline LV end-systolic dimension, mm & $28.6 \pm 2.4$ & $28.8 \pm 3.1$ & 0.711 \\
\hline LV ejection fraction, $\%$ & $59.1 \pm 5.9$ & $59.1 \pm 4.9$ & 0.980 \\
\hline Septal wall thickness, mm & $11.1 \pm 1.6$ & $11.1 \pm 1.8$ & 0.913 \\
\hline Posterior wall thickness, $\mathrm{mm}$ & $10.6 \pm 1.4$ & $10.6 \pm 1.6$ & 0.982 \\
\hline $\mathrm{E} / \mathrm{A}$ ratio & $0.83 \pm 0.17$ & $0.86 \pm 0.15$ & 0.199 \\
\hline $\mathrm{E} / \mathrm{Em}$ ratio & $8.7 \pm 1.7$ & $8.1 \pm 2.0$ & 0.103 \\
\hline TAPSE, $\mathrm{cm}$ & $2.1 \pm 0.2$ & $1.9 \pm 0.2$ & $<0.001$ \\
\hline $\mathrm{Sm} \mathrm{RV}, \mathrm{m} / \mathrm{s}$ & $13.0 \pm 3.4$ & $10.7 \pm 2.8$ & $<0.001$ \\
\hline RV FAC, \% & $47.2 \pm 5.1$ & $41.5 \pm 6.9$ & $<0.001$ \\
\hline RV MPI & $0.38 \pm 0.08$ & $0.44 \pm 0.08$ & $<0.001$ \\
\hline PAPs, mm Hg & $29.5 \pm 5.4$ & $34.6 \pm 8.3$ & $<0.001$ \\
\hline mMRC dyspnea score 3-4 & $6(9.5)$ & $37(51.4)$ & $<0.001$ \\
\hline Six-minute walk distance, $\mathrm{m}$ & $354.7 \pm 117.7$ & $210.8 \pm 116.5$ & $<0.001$ \\
\hline
\end{tabular}

Figures denote mean \pm SD or $\mathrm{n}(\%) . \mathrm{DBP}=$ Diastolic blood pressure; eGFR = estimated glomerular filtration rate; $\mathrm{HDL}=$ high-density lipoprotein; $\mathrm{LDL}=$ low-density lipoprotein; $\mathrm{PaCO}_{2}=$ arterial carbon dioxide pressure; $\mathrm{PaO}_{2}=$ arterial oxygen pressure; $\mathrm{SBP}=$ systolic blood pressure; $\mathrm{SO}_{2}=$ arterial oxygen saturation.

later, the first operator repeated the analysis to assess the intraobserver variability. Agreement analysis of interand intraobserver variability for RVFW-S measurements revealed high agreement, i.e. a mean difference of 0.09 (95\% limit of agreement $-0.99,1.16)$ and an intraclass correlation coefficient of 0.993 (95\% CI 0.983-0.997), respectively. Agreement analysis of interobserver variability for RVSW-S was a mean difference of -0.05 (95\% limit of agreement $-0.71,0.61)$ and the intraclass correlation coefficient for RVSW-S was 0.972 (95\% CI 0.931-0.989). 


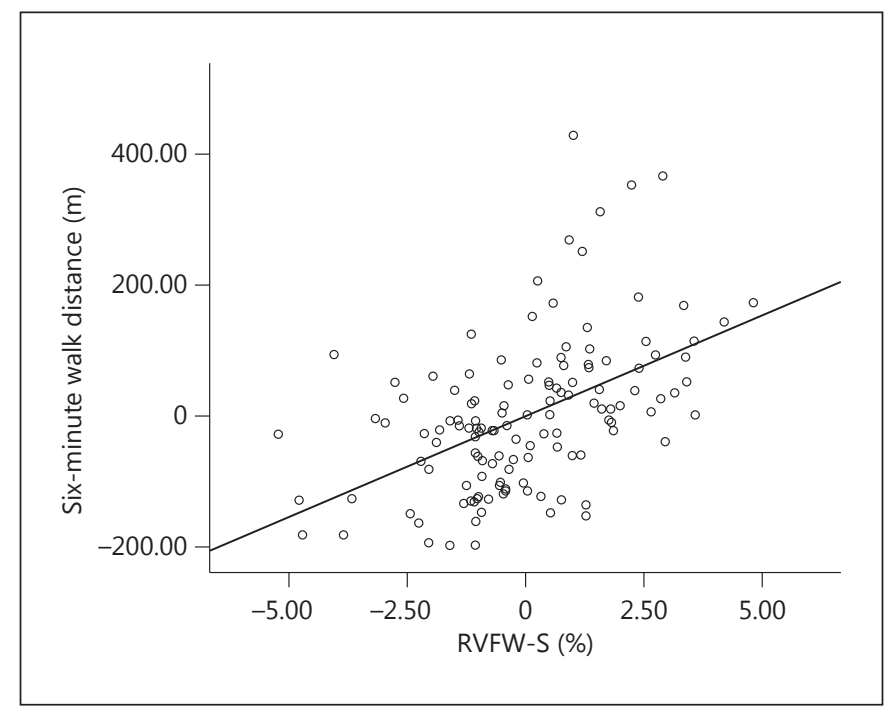

Fig. 2. The partial correlation of $\mathrm{FEV}_{1} \%$ predicted and 6-min walk distance with RVFW-S after adjusted for parameters of blood gas analysis, i.e. $\mathrm{FEV}_{1} \%$ predicted.

\section{Discussion}

This study demonstrated that increased BODE index parameters were associated with progressive impairment of RV systolic functions in COPD patients, assessed by 2D-STE-derived RVFW strain. Six-minute walk distance was found to be positively correlated with RVFW-S after adjustment for $\mathrm{FEV}_{1} \%$ predicted. To the best of our knowledge, this study is also the first to show the independent association between BODE index quartiles and $\mathrm{RV}$ dysfunction in subjects with COPD.

There is growing evidence that COPD is not only characterized by a chronic airflow limitation, but is also a systemic disease. Some extrapulmonary disorders such as cardiovascular disease, peripheral skeletal muscle dysfunction, diabetes and chronic kidney disease, are frequently seen in individuals with COPD. It has thus been proposed that COPD is in fact part of a chronic systemic inflammatory disease [22]. COPD is defined functionally according to $\mathrm{FEV}_{1}$ in the guidelines of the Global Initiative for Chronic Obstructive Lung Disease (GOLD) [1]. In previous reports, $\mathrm{FEV}_{1}$ was found to be independently associated with prognosis and the exacerbation of COPD [9]. However, evaluating $\mathrm{FEV}_{1}$ only is insufficient to describe the mortality and clinical conditions of COPD, which is complex and involves more than airflow obstruction [22]. Celli et al. [6] introduced a new multidimensional grading system, the BODE index, incorporat- ing the systemic (i.e. BMI and exercise capacity) and functional (airflow obstruction and dyspnea) components of COPD. The BODE index was found to be a better predictor of death from any cause and from respiratory causes than the $\mathrm{FEV}_{1}$ value.

Cardiovascular disease is one of the leading causes of mortality in patients with COPD. The RV is a conduit between the systemic and pulmonary circulation that is affected by the vascular remodeling induced by the systemic and local effects of COPD. In other words, COPD mainly affects the structure and functions of the RV. The evaluation of RV functions in COPD patients is crucial because of the relationship between RV dysfunction and increased mortality $[15,23]$. Although both RV functions and BODE index predict increased mortality in COPD patients, the relationship between them has not been studied up to now (except for the individual components of BODE index). RV dysfunction occurs in the early phase of lung involvement in COPD patients, but clinical signs are occult unless signs of systemic congestion are present (these develop in the later stages of the disease). Therefore, the evaluation of RV function by noninvasive methods has gained importance. In clinical practice, 2D echocardiography is the most frequently used noninvasive method for this evaluation. It is accompanied by important limitations, however, including the complex geometry of the RV, the predominantly longitudinal orientation of its myofibrils and poor echogenicity in COPD patients [15, 23]. 2D-STE is a new technique which permits the differentiation of active motion from passive motion, independent of the Doppler angle of incidence, tethering effect and load dependency. This differentiation represents a part of the stress-strain relationships that define myocardial contractility. Thus, strain can be decreased even in the setting of normal contractility if regional or global stress, e.g. afterload, is elevated. This is even more pronounced in the setting of RV circulation, which is especially sensitive to afterload elevation and may be useful for evaluating subtle changes when compared with other conventional echocardiographic techniques [24, 25].

In previous studies, 6-min walk distance and BMI, which reflect the systemic manifestation of COPD, were found to be associated with increased mortality $[26,27]$. Other studies evaluated the impact of exercise capacity and BMI on RV functions. In contrast to our results, Cuttica et al. [28] reported that structural changes in the RV, including RV wall thickness and right atrial area, were associated with a decrement in 6-min walk distance in nonsevere COPD patients, independent of lung function. They did not find an association between exercise capac- 
ity and RV functions as assessed by TAPSE or RV FAC. Their study included patients with nonsevere COPD, classified according to GOLD criteria, and the study population consisted of different races such as Hispanic, Asian, black and white, with Caucasians being predominant. The clinical characteristics of patients, such as blood pressure, smoking history and fasting plasma glucose levels were not defined. The impact on RV functions and exercise capacity of COPD severity, racial variations and clinical characteristics could explain why the results of their study were not compatible with ours. In another study, Schoos et al. [29] investigated the echocardiographic predictors of exercise capacity in COPD patients. They reported that tricuspid regurgitation was the only independent predictor of exercise tolerance among RV functional parameters including RVFW-S. There may be several explanations for their conflicting results. The study population was enrolled according to the GOLD classification and $84 \%$ had GOLD class II-III COPD. There was no detailed information about past medical history or the latest exacerbations of COPD. Inclusion and exclusion criteria were also not explained clearly; for instance, factors like obstructive sleep apnea could have affected RV function and interfered with the interpretation of the findings.

In our study, RVFW-S was positively correlated with 6-min walk distance after adjustment for $\mathrm{FEV}_{1} \%$ predicted. RV systolic function, which is especially sensitive to afterload elevation, is even more pronounced in the setting of COPD [24, 25]. Fluctuations of pulmonary artery pressure and an increase in venous blood return into the RV during exercise may explain the relationship between exercise capacity and RV deformation. Patients in our study with a BMI $\leq 21$ had a lower RVFW-S value than those with a BMI $>21$. Reduced muscle mass and cachexia are associated with increased mortality in COPD [26]. The mechanism involved in the loss of muscle mass and in skeletal muscle atrophy seems to be related to systemic inflammation and oxidative stress through reducing protein synthesis and accelerating protein catabolism. Furthermore, cardiac myocytes, i.e. protein-rich tissue, may be affected by similar proteolytic processes $[15,30$, 31]. RV myocardium and functions might be affected through this pathophysiological mechanism in COPD patients with a low BMI.

$\mathrm{FEV}_{1}$ reflects the degree of pulmonary impairment and is a well-known predictor of mortality in COPD. A link between RV functions and $\mathrm{FEV}_{1}$ representing COPD severity has been evaluated. In line with our findings, $\mathrm{Vi}$ tarelli et al. [32] reported that strain-rate imaging param- eters are correlated with respiratory function tests in COPD patients. In our study, RVFW-S was positively correlated with $\mathrm{FEV}_{1} \%$ predicted. In a previous report, $\mathrm{FEV}_{1} \%$ predicted was associated with systemic inflammation [33]. Impaired respiratory functions and subsequent hypoxemia usually have a negative impact on RV functions, which could be further affected by the increased systemic inflammatory process. In our study, patients with an mMRC dyspnea score of 3-4 had a lower RVFW-S value than those with a score of $0-2$. The mMRC dyspnea scale reflects the perception by patients of symptoms related to skeletal muscle atrophy and loss of muscle mass as a consequence of the systemic manifestation of COPD $[6,30]$. A higher mMRC dyspnea score and a lower RVFW-S may contribute to common presentations that reflect increased systemic inflammation. Our findings about diastolic functions are in line with previous studies. Individuals with COPD had an increased E/Em ratio compared to the control group and this gradually decreased with increasing BODE index parameters. A reduction in LV filling pressure due to reduced preload and hyperinflation is probably the potential mechanism responsible for LV diastolic dysfunction in patients with COPD $[34,35]$. In our study, increased BODE index scores were associated with decreased RVFW-S, which could not be detected by conventional parameters that evaluate RV functions. In a similar manner, Giusca et al. [36] stated that RV functions could be better described with deformation imaging rather than conventional parameters, due to changes in apical transverse motion when RV dysfunction occurs.

The definition of COPD has evolved from a disease limited to the lungs to a multisystem disorder comprising pulmonary and systemic inflammation. This disease should thus be evaluated by multidimensional methods and managed with a multidisciplinary approach [22]. Multidimensional evaluation should include RV functions that can be directly influenced by the negative pulmonary and systemic effects of COPD. Although assessment of RV function could provide useful data for pulmonologist in terms of planning treatment and predicting prognosis, it is not easily obtained in pulmonary clinics. The BODE index is a multidimensional grading system and can be evaluated easily in office settings, but its relation to RV functions was not studied before now. This study provides essential information about the clinical implications of the relationship between the BODE index and RV functions. 


\section{Limitations}

The main limitation of this study was its relatively small sample size. Second, RV strain was assessed by 2DSTE software which was mainly developed for LV strain; however, previous studies did demonstrate acceptable feasibility and reproducibility for the RV strain. Third, the estimation of the PAPs was based only on tricuspid regurgitation measurements and an invasive pressure measurement was not used. However, this widely used Doppler-derived pressure estimation is well recognized and has been documented as having good correlation with simultaneously obtained catheter-derived measurements. BODE index quartiles can vary in the course of time. Our study did not inform about the impact of BODE index quartile interchange on RV functions, necessitating further studies. Finally, we did not perform measurements of the diffusing capacity of carbon monoxide, but these are not strictly necessary for the diagnosis of COPD.

\section{Conclusion}

The BODE index is an easily calculated multidimensional grading system for evaluating COPD patients in pulmonary clinics. It not only provides information about the pulmonary aspects of the disease such as airflow limitation, it also evaluates the systemic clinical manifestations. Our study revealed that assessment of the BODE index provides information about RV functions and that as the BODE index parameters increase, there is a decrement in RVFW-S as a sign of RV dysfunction.

\section{References}

1 Rabe KF, Hurd S, Anzueto A, Barnes PJ, Buist SA, Calverley P, Fukuchi Y, Jenkins C, Rodriguez-Roisin R, van Weel C, Zielinski J: Global Initiative for Chronic Obstructive Lung Disease. Global strategy for the diagnosis, management, and prevention of chronic obstructive pulmonary disease: GOLD executive summary. Am J Respir Crit Care Med 2007; 176:532-555.

-2 Murray CJ, Lopez AD: Mortality by cause for eight regions of the world: Global Burden of Disease Study. Lancet 1997;349:1269-1276.

-3 Continuous or nocturnal oxygen therapy in hypoxemic chronic obstructive lung disease: a clinical trial. Nocturnal Oxygen Therapy Trial Group. Ann Intern Med 1980;93:391398.

-4 Gerardi DA, Lovett L, Benoit-Connors ML, Reardon JZ, ZuWallack RL: Variables related to increased mortality following out-patient pulmonary rehabilitation. Eur Respir J 1996; 9:431-435.

5 van Eeden SF, Sin DD: Chronic obstructive pulmonary disease: a chronic systemic inflammatory disease. Respiration 2008;75: 224-238.

6 Celli BR, Cote CG, Marin JM, Casanova C, Montes de Oca M, Mendez RA, Pinto Plata V, Cabral HJ: The body-mass index, airflow obstruction, dyspnea, and exercise capacity index in chronic obstructive pulmonary disease. N Engl J Med 2004;350:1005-1012.

7 Ong KC, Earnest A, Lu SJ: A multidimensional grading system (BODE index) as predictor of hospitalization for COPD. Chest 2005; 128 : 3810-3816.

8 Cote CG, Dordelly LJ, Celli BR: Impact of COPD exacerbations on patient-centered outcomes. Chest 2007;131:696-704.
-9 Faganello MM, Tanni SE, Sanchez FF, Pelegrino NR, Lucheta PA, Godoy I: BODE index and GOLD staging as predictors of 1-year exacerbation risk in chronic obstructive pulmonary disease. Am J Med Sci 2010;339:10-14.

10 Suissa S: Co-morbidity in COPD: the effects of cardiovascular drug therapies. Respiration 2010;80:3-7.

11 Anthonisen NR, Skeans MA, Wise RA, Manfreda J, Kanner RE, Connett JE: Lung Health Study Research Group. The effects of a smoking cessation intervention on 14.5-year mortality: a randomized clinical trial. Ann Intern Med 2005;142:233-239.

12 Burgess MI, Mogulkoc N, Bright-Thomas RJ, Bishop P, Egan JJ, Ray SG: Comparison of echocardiographic markers of right ventricular function in determining prognosis in chronic pulmonary disease. J Am Soc Echocardiogr 2002;15:633-639.

13 Akcay M, Yeter E, Durmaz T, Keles T, Akar Bayram N, Uyar M, Davutoglu V, Yüksel I, Kurt M, Bozkurt E: Treatment of acute chronic obstructive pulmonary disease exacerbation improves right ventricle function. Eur J Echocardiogr 2010;11:530-536.

14 van Gestel AJ, Kohler M, Steier J, Teschler S, Russi EW, Teschler H: The effects of controlled breathing during pulmonary rehabilitation in patients with COPD. Respiration 2012;83:115-124.

15 Sabit R, Bolton CE, Fraser AG, Edwards JM, Edwards PH, Ionescu AA, Cockcroft JR, Shale DJ: Sub-clinical left and right ventricular dysfunction in patients with COPD. Respir Med 2010;104:1171-1178.

16 Jurcut R, Giusca S, La Gerche A, Vasile S, Ginghina C, Voigt JU: The echocardiographic assessment of the right ventricle: what to do in 2010? Eur J Echocardiogr 2010;11:81-96.
17 Imai E, Horio M, Nitta K, Yamagata K, Iseki $\mathrm{K}$, Tsukamoto Y, Ito S, Makino H, Hishida A, Matsuo S: Modification of the Modification of Diet in Renal Disease (MDRD) Study equation for Japan. Am J Kidney Dis 2007;50:927937.

18 Standardization of Spirometry, 1994 update. American Thoracic Society. Am J Respir Crit Care Med 1995;152:1107-1136.

19 Russi EW, Karrer W, Brutsche M, Eich C, Fitting JW, Frey M, Geiser T, Kuhn M, Nicod L, Quadri F, Rochat T, Steurer-Stey C, Stolz D; Swiss Respiratory Society: Diagnosis and management of chronic obstructive pulmonary disease: the Swiss guidelines. Official guidelines of the Swiss Respiratory Society. Respiration 2013;85:160-174.

20 Rudski LG, Lai WW, Afilalo J, Hua L, Handschumacher MD, Chandrasekaran K, Solomon SD, Louie EK, Schiller N: Guidelines for the echocardiographic assessment of the right heart in adults: a report from the American Society of Echocardiography endorsed by the European Association of Echocardiography, a registered branch of the European Society of Cardiology, and the Canadian Society of Echocardiography. J Am Soc Echocardiogr 2010;23:685-713, quiz 786-788.

21 Gottdiener JS, Bednarz J, Devereux R, Gardin J, Klein A, Manning WJ, Morehead A, Kitzman D, Oh J, Quinones M, Schiller NB, Stein JH, Weissman NJ: American Society of Echocardiography: recommendations for use of echocardiography in clinical trials; a report from the American Society of Echocardiography. J Am Soc Echocardiogr 2004;17:10861119.

22 Nussbaumer-Ochsner Y, Rabe KF: Systemic manifestations of COPD. Chest 2011;139: 165-173. 
23 Tayyareci Y, Tayyareci G, Tastan CP, Bayazit $P$, Nisanci Y: Early diagnosis of right ventricular systolic dysfunction by tissue Dopplerderived isovolumic myocardial acceleration in patients with chronic obstructive pulmonary disease. Echocardiography 2009;26: 1026-1035.

24 Hardegree EL, Sachdev A, Villarraga HR, Frantz RP, McGoon MD, Kushwaha SS, Hsiao JF, McCully RB, Oh JK, Pellikka PA, Kane GC: Role of serial quantitative assessment of right ventricular function by strain in pulmonary arterial hypertension. Am J Cardiol 2013;111:143-148.

-25 Fukuda Y, Tanaka H, Sugiyama D, Ryo K, Onishi T, Fukuya H, Nogami M, Ohno Y, Emoto N, Kawai H, Hirata K: Utility of right ventricular free wall speckle-tracking strain for evaluation of right ventricular performance in patients with pulmonary hypertension. J Am Soc Echocardiogr 2011;24:11011108.

26 Schols AM, Broekhuizen R, Weling-Scheepers CA, Wouters EF: Body composition and mortality in chronic obstructive pulmonary disease. Am J Clin Nutr 2005;82:53-59.
27 Pinto-Plata VM, Cote C, Cabral H, Taylor J, Celli BR: The 6-min walk distance: change over time and value as a predictor of survival in severe COPD. Eur Respir J 2004;23:28-33.

28 Cuttica MJ, Shah SJ, Rosenberg SR, Orr R, Beussink L, Dematte JE, Smith LJ, Kalhan R: Right heart structural changes are independently associated with exercise capacity in non-severe COPD. PLoS One 2011;6:e29069.

29 Schoos MM, Dalsgaard M, Kjærgaard J, Moesby D, Jensen SG, Steffensen I, Iversen KK: Echocardiographic predictors of exercise capacity and mortality in chronic obstructive pulmonary disease. BMC Cardiovasc Disord 2013;13:84.

30 Jackman RW, Kandarian SC: The molecular basis of skeletal muscle atrophy. Am J Physiol Cell Physio 2004;287:C834-C843.

31 Gan WQ, Man SF, Senthilselvan A, Sin DD: Association between chronic obstructive pulmonary disease and systemic inflammation: a systematic review and a meta-analysis. Tho$\operatorname{rax} 2004 ; 59: 574-580$

32 Vitarelli A, Conde Y, Cimino E, Stellato S, D’Orazio S, D'Angeli I, Nguyen BL, Padella V, Caranci F, Petroianni A, D’Antoni L, Terzano C: Assessment of right ventricular function by strain rate imaging in chronic obstructive pulmonary disease. Eur Respir J 2006;27:268275.
33 Donaldson GC, Seemungal TA, Patel IS, Bhowmik A, Wilkinson TM, Hurst JR, Maccallum PK, Wedzicha JA: Airway and systemic inflammation and decline in lung function in patients with COPD. Chest 2005;128: 1995-2004.

- 34 Boussuges A, Pinet C, Molenat F, Burnet H, Ambrosi P, Badier M, Sainty JM, Orehek J: Left atrial and ventricular filling in chronic obstructive pulmonary disease. An echocardiographic and Doppler study. Am J Respir Crit Care Med 2000;162:670-675.

35 Watz H, Waschki B, Meyer T, Kretschmar G, Kirsten A, Claussen M, Magnussen H: Decreasing cardiac chamber sizes and associated heart dysfunction in COPD: role of hyperinflation. Chest 2010;138:32-38.

- 36 Giusca S, Dambrauskaite V, Scheurwegs C, D'hooge J, Claus P, Herbots L, Magro M, Rademakers F, Meyns B, Delcroix M, Voigt JU: Deformation imaging describes right ventricular function better than longitudinal displacement of the tricuspid ring. Heart 2010 96:281-288. 